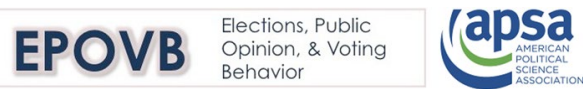

\section{EPOVB Award Winners 2019}

(c) Springer Science+Business Media, LLC, part of Springer Nature 2019

APSA's Elections, Public Opinion, and Voting Behavior Section is delighted to announce our 2019 Award Winners.

The Philip E. Converse Book Award goes to Donald Green, Bradley Palmquist, and Eric Schickler for Partisan Hearts and Minds: Political Parties and the Social Identities of Voters (Yale University Press, 2002). The Converse Award is awarded annually to the author(s) of an outstanding book published at least five years ago.

Anand Sokhey (University of Colorado Boulder) is the winner of our Emerging Scholar Award, presented to a top scholar in the field who is within ten years of the Ph.D.

The Best Paper Award is awarded annually for the best paper delivered at one of the section's panels at the previous year's APSA. This year the award goes to two sets of collaborating scholars: Maggie Deichert, Stephen N. Goggin, and Alexander Theodoridis for their paper "God, Sex, and Especially Politics: Disentangling the Dimensions of Discrimination" and Sara B. Hobolt, Thomas J. Leeper, and James Tilley, for their paper "Divided by the Vote." Both papers were presented at the 2018 APSA meeting in Boston.

Cecilia H. Mo's article "Perceived Relative Deprivation and Risk: An Aspiration-Based Model of Human Trafficking Vulnerability" (Political Behavior 40(1):247-77) was selected as the Best Article in Political Behavior in 2018.

The John Sullivan Award, for the best paper presented by a graduate student at one of the section's panels at the previous year's APSA, goes to Bradley Spahn (Stanford University) for his paper "Before Stable Partisanship."

Caitlin Davies (Stony Brook University), Brian Hamel (UCLA), Aykut Ozturk (Syracuse University), and Elizabeth Schmitt (Arizona University) were each awarded a travel award to support their participation in the 2019 APSA annual meeting.

Congratulations to all the winners!

Publisher's Note Springer Nature remains neutral with regard to jurisdictional claims in published maps and institutional affiliations. 